\title{
INTERFEROMETRIC DETERMINATION OF THE OPTICAL CONSTANTS OF THIN METALLIC FILMS OF ANTIMONY AND SILVER
}

\author{
N. Barakat \\ Faculty of Science, Ain Shams University Cairo, Egypt \\ S. Mokhtar, M.S. Shaalan, M. Sobee, and F. Abdel Aziz \\ National Institute of Standards, Cairo, Egypt. \\ and W. Osman \\ Faculty of Science, Cairo University Cairo, Egypt.
}

\section{Abstract:}

Measurement of the change of phase in transmission through vacuum evaporated films of Antimony and Silver were carried out. Both real and imaginary parts of the complex refractive index were thus evaluated. The method has been applied to deduce the optical ocnstants of thin films of Silver and Antimony. Previous data on Bismuth and Manganese is utilized to deduce their extinction coefficients.

\section{Introduction and Previous Works}

A thin sbsorbing film deposited an a nan-absorbing substrate may be characterised by its thickness $d$, the potical constants $n$ and $k$ where $\hat{n}=n+i k$ is the complex refractive indox at the wavelength $\lambda$ of the incident radietion. $K$ is the extinction coefficient related to the absorption coefficient by the relation $\alpha=\frac{4 \pi}{\lambda} \mathrm{kd}$, (1), $n$ the real part of the complex refractive index is usually termed the refractive index of the film.

Classically the optical constants $n$ and $k$ are determined from measurements on the reflected intensities, where the light in fact desls only with the surface layers of the film. The inner most layers formed at the early stages af nucleation with their peculiar structural properties do not contribute critically to the mensured surface reflectivity. Reviews of such methods may be referred to in $(2),(3),(4)$.

However, the phase changes accampaning reflection end transmission at air/film interface ate not only sensitive quantitics to changes in $n$ and $k$, (2), but also readily and accurately messured by interferometric techniques, $\langle 5\rangle$, (6). Studies on the behaviour of the phese quantities as function of $d$ and reveal their dependence on $1 \mathrm{izm}$ thickness and structure, (7), (9). Recent publications, Garakay et $8 \mathrm{l} .(9),(10)$ on the dotermination of $\mathrm{n}$ and $\mathrm{k}$ for $\mathrm{Mn} \& \mathrm{Bi}$ and for $\mathrm{Au}$ and $\mathrm{Te}$ from measurements 
of the change of phase in transmiasion as function of d showed two distinct ranges of behaviour, a non lineaf variatian showing maxima and minima for film thicknesses below a critical value $d_{c}$ and $c$ cleat straight line portian for $d \geqslant d_{c}$ where the tilm behaves as bulk like. The present papet further uses $\gamma_{\text {va }}$ d straight line vatiation for $d \partial d_{c}$ to determine $n$ and $k$ for Silvet and Antimany lilms. Also the constant $k$ is determined for manganese and bismuth films.

\section{The principle of the method:}

The phase change in transmission $\gamma$ of monochramatic radietion $\lambda$ incident on is homogeneaus and isotropic thick film of thickness $d$ and complex refractive index $n_{1}=n_{1}+i k_{1}$ situated between two dielectric medil is given approximately by

$$
\gamma=\psi_{01}+\psi_{12}+\frac{2 \pi}{\lambda} n_{1} d
$$

This formula nasumes that the effect of multiple roflections within the rilm bounderies censed, due to the combined effect of nbsatption and thickness. The efiterion is that $\operatorname{Exp}(2 \mathrm{k}\}) \geqslant 100$ where $\}=\frac{2 \pi}{\lambda} d$, this wauld correspand acproximately to
single air/film ieflection.

In eqn $(1), Y_{01}$, and $Y_{12}$ are the phase changes at reflection at the first and second film surfaces and givan by

$$
\begin{aligned}
& \psi_{01}=\tan ^{-1} \frac{-k_{1}}{n_{0}+n_{1}} \\
& \psi_{12}=\tan ^{-1} \frac{n_{2} k_{1}}{n_{1}^{2}+k_{1}^{2}+n_{2} n_{1}}
\end{aligned}
$$

$n_{2}$ is the refractive index of the glass substrate and is teken to be 1.SO. The expesimental cutves giving relative to air nre represonted by

$$
\gamma=\psi_{01}+\psi_{12}+\frac{2 \pi}{\lambda}\left(n_{1}-1\right) d
$$

clearly $Y$ in the last expression (2) represents $B$ straight line rclation between $d$ and with $\Psi_{01}$ and $\Psi_{12}$ constants. The slope is $\frac{2 V}{\lambda}\left(n_{1}-1\right)$ d where $\gamma$ is taken as fractinn of

The intereept of the straight line on the exis at $d=0$ would be

$$
\begin{gathered}
\gamma_{0}=\psi_{01}+\psi_{12} \\
\text { with, } \tan \gamma_{0}=\frac{\tan \psi_{01}+\tan \psi_{12}}{1-\tan \psi_{01} \tan \psi_{12}}
\end{gathered}
$$




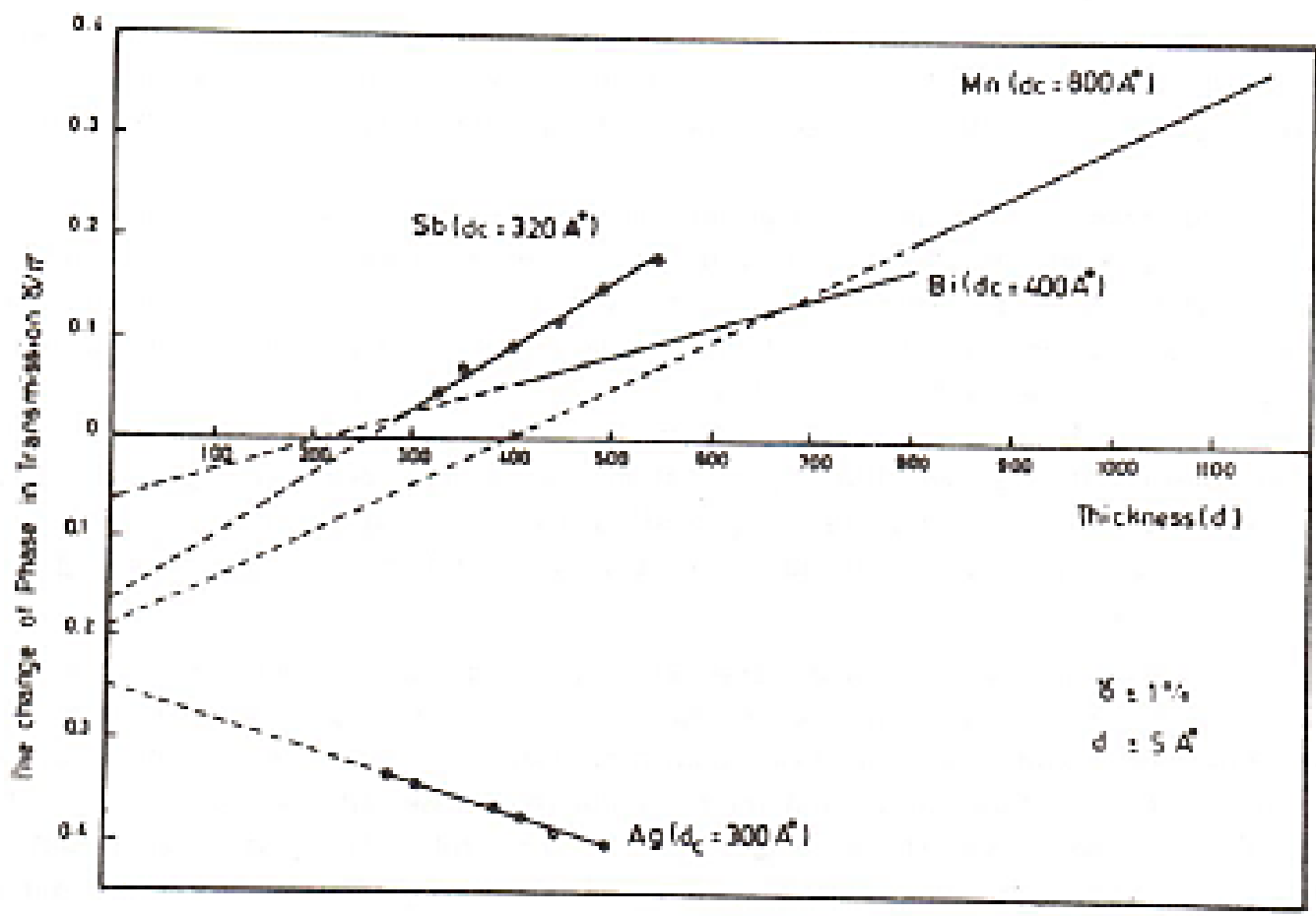

Fig (1) 
Substituting the values of $\tan \Psi_{01}$ and $\tan \Psi_{12}$ in (3) leads to

$k_{1}^{3}+k_{1}^{2}\left\langle n_{1}+2.5\right\rangle \tan \gamma_{0}+k_{1}\left\langle n_{1}^{2}-1.5\right\rangle+\left(n_{1}^{3}+2.5 n_{1}^{2}+1.5 n_{1}\right\rangle \tan \gamma_{0}=0$

The aptical eanstant $n_{1}$ is abtained from the slape of the straight line and then substitution in (4) fot $n_{1}$ and $\left(\gamma_{0}\right)_{E_{\times p}}$. would produce $k_{1}$ as the only teal toot of eqr $\{4\}$.

\section{Experimental procedure and results}

Antimany, silver, bismuth and manganese films were vacuum evaporated on gless substrates at rate of some $20 \mathrm{~A}^{0} / \mathrm{S}$ Bt $10^{-5}$ Torr or better. Film thickness was determined by Tolansky's multiple beam interference technique at reflections(11).

The changa of phase in transmiasion relative to air was detarmined axperimentally for each individual film using the Rayleigh-Lowe refrectorneter following the technique uaed by Ehigura (12) nnd Barakat et al, (13), In the procedure two beams are allowed to intersect forming interference fringes after one beam has passod through the layer under study and the other beam through un air layer of the sarne thickness. The lower system farms the reference system for the two beams passing through air, the upoer system results from one beam passing through a layer of thickness (d) $A^{0}$. The fringe shift gives the change of phase in transenission as a fraction of order sepatation. The avetall uncertainty in determining $\gamma$ is of the otder of 1S\%.

Fig. (1) shows the straight line variation of $\mathrm{X}$ vs. \& tor Ag, antimony $\mathrm{\theta i}$ and Mn, each straight line starts at $\left(d_{c}\right)$ where $d_{c}$ is the thickness separating the nonstraight line properties from the bulk like behoviout. Table (1) gives the optical constants $n_{1}$ and $k_{1}$ for the four metals and their critical thicknesses $\left(d_{c}\right)$ at which the bulk like $\gamma$ vo. d behaviout starts. The tesults demonstrate tha ganaral availability of the intefferometric technique first used to obtain the opticel constants by Barakat et al. in (9), (10) provided that the film thickness is above the limiting value separating thin film and bulk like behaviour.

\section{Reterences:}

1. M. Born, E. Walf: "Principles of Cptics" Perqamon Press, Landon, (1975) p. 51.

2. O.S. Hesvenes "Optical Properties of Thin Solid Films", Dover, New Yotk, (1965) p. 51.

3. O.S. Heavenes In Physics of Thin Films, Val, 2, Ed. by C. Hass and R. Thun, Acadernic Press, New Yark, (1964), p. 209.

4. T. Abelese tbith, Vol. 6 (1971) p. 182.

5. N. Barakat, 5. Mokhtar and K. Abdel Hady, J.0.S.A. Vol. 54, No. 2, 213-216, (1964). 
6. L. Schulz, 1.0.5.A., Vol. 41, 1047, (1951).

7. J.C.M. Garnett, Trans, Roy. Soc. London, Ser. A, 203-3BS, (1904).

8. H. Schoppet, Z. Physe, Vol. 130, 565, (1951).

9. N. Baraknt, S. Mokhtat and Al-Houty, Appl. Phys, Vol. 20, p. 225, (1979).

10. N. Barakat et al, Optica Acto Vol. 29, No, 10, 1309-1312, (1932).

11. S. Tolensky, "Muitiple Beam Interferometry of Surfaces and Films", Oxford University Press, p. 149, (1948).

Table (1): Dptical constants of Eulk Metals at $5875 \mathrm{~A}^{\circ}$

\begin{tabular}{|l|c|c|}
\hline Mctal & $n$ & $k$ \\
\hline Antimony & 3.2 & 4.48 \\
\hline Bismuth & 1.76 & 1.35 \\
\hline Manganese & 2.41 & 3.79 \\
\hline Silver $\lambda$ S460 An & 0.51 & 3.32 \\
\hline
\end{tabular}

